\section{Retinal nerve fiber layer and optic disc measurements by spectral domain OCT: normative values and associations in young adults}

YM Tariq, H Li, G Burlutsky and P Mitchell

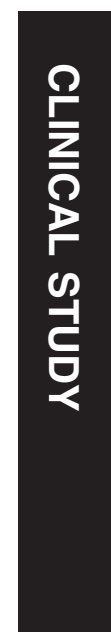

Eye (2012) 26, 1563-1570; doi:10.1038/eye.2012.216; published online 19 October 2012

Keywords: retinal nerve fiber layer; optic disc; optical coherence tomography; Sydney Childhood Eye Study

\section{Introduction}

In glaucoma, thinning of the retinal nerve fiber layer (RNFL) can occur before the onset of detectable visual field loss. ${ }^{1,2}$ Optical coherence tomography (OCT) is an imaging modality which can be used to non-invasively measure retinal parameters. It is of great use in diagnosis and monitoring of diseases affecting retinal and optic nerve structure and can also be used to detect RNFL thinning in glaucomatous eyes. ${ }^{3}$

Spectral domain OCT is currently the most advanced commercially available application of OCT technology. It allows faster scanning and higher resolution images than time domain OCT technology. ${ }^{4,5}$ The Cirrus HD-OCT 4000 (Carl Zeiss Meditec, Dublin, CA, USA) is a spectral domain OCT instrument that scans the optic disc and peripapillary RNFL in a $6-\mathrm{mm}^{2}$ area consisting of $200 \times 200$ scanning grid. The instrument software has an in-built normative database to compare with RNFL parameters. RNFL and optic disc parameters, however, are known to vary owing to particular demographic $^{6-8}$ and ocular factors. ${ }^{7,9-12}$ Most studies to have assessed variation in these parameters have been performed using the older time domain Stratus OCT. As results using
Centre for Vision Research, Department of Ophthalmology and Westmead Millennium Institute, University of Sydney, Sydney, New South Wales, Australia

Correspondence: Dr P Mitchell, Centre for Vision Research, Department of Ophthalmology, Westmead Hospital, Hawkesbury Road, Westmead, Sydney, NSW 2145, Australia Tel: + 6129845 7960; Fax: + 61298458345 . E-mail: paul.mitchell@ sydney.edu.au

Received: 14 July 2011 Accepted in revised form: 11 September 2012 Published online: 19 October 2012 
the Cirrus HD-OCT and Stratus OCT are not interchangeable, ${ }^{13}$ studies assessing these relationships with Cirrus HD-OCT are needed.

The purpose of this study is to determine normal values for Cirrus HD-OCT-measured RNFL and optic disc parameters in a large population-based sample of young adults aged 16-19 years, and to determine whether demographic and ocular factors impact on these measurements. We believe that this young population is ideal for such investigations as they are relatively free of confounding ocular disease.

\section{Materials and methods}

\section{Population}

The Sydney Adolescent Vascular and Eye Study (SAVES) is a 5-year follow-up of the Sydney Myopia Study (SMS), and is part of the Sydney Childhood Eye Study. The SMS was a population-based survey of refraction and other eye conditions in a sample of school students, across 34 primary and 21 high schools conducted between 2003 and 2005. As part of this survey, all schools in Sydney were stratified into 10 deciles based on socio-economic status (SES) of the areas in which they were located, with three high schools chosen from the top SES decile and the remainder randomly selected from the bottom 9 deciles. SES data were obtained from the Australian Bureau of Statistics 2001 national census. The high school students were examined in grade 7 between 2004 and 2005 . As part of SAVES, 20 of the 21 high schools were re-visited during 2009 and 2010 and students in grades 11 and 12 were offered the opportunity to participate.

\section{Procedures}

Each participant under age 18 years was required to provide written consent from one parent, and those participants over 18 years of age were permitted to consent independently. The study followed the tenets of the Declaration of Helsinki. The study was approved by the Human Research Ethics Committee, University of Sydney and the New South Wales Department of Education and Training.

Examinations were conducted during 2009 and 2010 by a team of doctors, optometrists, and orthoptists. Monocular visual acuity was assessed using a logarithm of the minimum angle of resolution (logMAR) chart, read at $244 \mathrm{~cm}$ (8 feet). ${ }^{14}$ Both cyclopentolate (1\%) and tropicamide ( $1 \%$ ) were administered twice ( $5 \mathrm{~min}$ apart) to achieve cylcoplegia; in addition, phenylephrine $(2.5 \%)$ was used if adequate mydriasis ( $\geq 6 \mathrm{~mm}$ ) was not achieved and for individuals with very dark iris pigmentation. Axial length (AL) was measured using non-contact partial coherence interferometry (IOLMaster; Carl Zeiss, Jena, Germany). Autorefraction (RK-F1; Canon, Tokyo, Japan) was performed at least 25 min after the eye drops. Fundus photography (CF 60DSI) was also performed. All tests were conducted on both eyes.

Scans of RNFL thickness and the optic disc were performed using a Cirrus HD-OCT 4000, which performs low-coherence interferometry with an 840-nm superluminescent light-emitting diode to produce high-resolution tomograms. Data for RNFL and optic disc parameters were acquired using the 'Optic Disc Cube $200 \times 200^{\prime}$ protocol, after pupil dilation. This protocol scans a 6-mm square grid ('cube') by acquiring a series of 200 horizontal scan lines each composed of 200 A-scans.

A single operator (HL) performed the optic disc scans on each participant. The operator was required to ensure adequate pupil alignment, optimal fundus focus and illumination as well as centration of the optic disc before each scan. Scans were repeated in an attempt to obtain signal strengths $\geq 8 / 10$ and to avoid blink or eye movement artifacts.

Cirrus HD-OCT software (version 5.0) was used for image analysis. RNFL thickness was calculated by layerseeking algorithms for the entire cube. A total of 256 specific A-scans aligned in a circle of $3.46 \mathrm{~mm}$ diameter centered on the optic disc are extracted to provide average RNFL thickness and data in clock hours and quadrants. This circle is automatically placed by the software. In some cases where the operator deemed the circle to be eccentrically located, it was manually moved to be centered on the optic disc before data were exported for analysis.

The OCT software provides calculation of optic nerve head parameters. The software delineates the disc edge by the termination of Bruch's membrane. The neuroretinal rim width and area is determined by measuring the amount of neuroretinal tissue within the boundaries of the optic nerve. The software thus calculates optic disc rim and optic cup area. The total area of the optic disc is the sum of the rim and cup areas. The average cup/disc ratio (CDR) is the square root of the ratio of the area of the cup to the area of the disc. The vertical CDR is the ratio of vertical cup diameter to vertical disc diameter. Cup volume is the volume between the plane created by the cup outline at the vitreous interface and the posterior surface of the optic nerve head.

\section{Statistics}

Statistical analysis was performed using SAS, Version 9.2 (SAS Institute, Cary, NC, USA). For the purposes of this report, only scans of the right eye with signal strengths greater than 7 were used in analysis. The Kolmogorov-Smirnov test 
was used to assess for normality of the distributions. Paired $t$-tests were used to compare RNFL quadrant data. For comparison of parameters between sex and ethnicity, mixed linear models ${ }^{15}$ were employed adjusting for age, height, AL, and sex/ethnicity with the school attended included as a random effect. Mixed linear models were also employed in assessing the relationships of RNFL thickness with AL, refraction, and optic disc parameters, adjusting for age, height, AL, sex, and ethnicity with the school attended included as a random effect.

\section{Results}

Of the 2294 students offered examinations, 1550 (67.6\%) students between the ages of 16 and 19 years had OCT scanning performed. Of these, 9 participants were excluded because of signal strengths $<8$ for optic disc scans; 5 were excluded because of ocular pathology, including retinitis pigmentosa, posterior staphyloma and prior optic nerve injury, and another 15 were excluded because their best corrected visual acuity was 20/40 or worse, leaving 1521 with OCT scans included in analysis. Table 1 presents baseline characteristics from the sample. The mean age of the sample was $17.3 \pm 0.6$ years and $49.6 \%$ were male.

Table 2 presents the distributions of RNFL and optic disc parameters. The average RNFL for this population was $99.4 \pm 9.7 \mu \mathrm{m}$ with a range of $61-138 \mu \mathrm{m}$. The inferior RNFL quadrant was the thickest at $128.5 \pm 17.2 \mu \mathrm{m}$ followed by the superior quadrant at $124.8 \pm 15.9 \mu \mathrm{m}$. The two thinnest quadrants were the nasal RNFL at $74.2 \pm 12.6 \mu \mathrm{m}$ and the temporal RNFL at $69.9 \pm 11.6 \mu \mathrm{m}$.

Table 1 Characteristics of participants

\begin{tabular}{|c|c|c|c|}
\hline Characteristic & $\begin{array}{c}\text { All } \\
(\mathrm{n}=1521)\end{array}$ & $\begin{array}{c}\text { White } \\
(\mathrm{n}=841)\end{array}$ & $\begin{array}{c}\text { East Asian } \\
(\mathrm{n}=301)\end{array}$ \\
\hline Age, years & $17.3 \pm 0.6^{\mathrm{a}}$ & $17.4 \pm 0.48$ & $17.4 \pm 0.7$ \\
\hline Male, $n(\%)$ & 755 (49.6) & $448(53.3)$ & $129(42.9)$ \\
\hline \multicolumn{4}{|l|}{ Ethnicity $n,(\%)$} \\
\hline White & 841 (55.3) & & \\
\hline East Asian & 301 (19.8) & & \\
\hline South Asian & $101(6.6)$ & & \\
\hline Middle Eastern & $133(8.7)$ & & \\
\hline Other & $145(9.5)$ & & \\
\hline SER, D & $0.08 \pm 1.56^{\mathrm{b}}$ & $0.55 \pm 1.02$ & $-1.12 \pm 2.12$ \\
\hline $\mathrm{AL}, \mathrm{mm}$ & $23.7 \pm 0.9^{c}$ & $23.5 \pm 0.8$ & $24.1 \pm 1.2$ \\
\hline Height, cm & $169.4 \pm 9.6$ & $171.9 \pm 9.5$ & $164.9 \pm 8.7$ \\
\hline Weight, kg & $66.2 \pm 22.0$ & $67.6 \pm 14.8$ & $61.5 \pm 38.8$ \\
\hline
\end{tabular}

These differences in thickness between RNFL quadrants were highly statistically significant $(P<0.0001)$. The thickest RNFL clock hour segments were at the 7 (inferotemporal) and 11 (superotemporal) o'clock positions, with the thinnest at the 3 (nasal) and 9 (temporal) o'clock positions. The mean disc area in this population was $1.98 \pm 0.38 \mathrm{~mm}^{2}$ with a mean rim area of $1.50 \pm 0.30 \mathrm{~mm}^{2}$ and a mean CDR of $0.44 \pm 0.18$. CDRs ranged from 0.05 to 0.80 .

Females $(n=766)$ had a thicker temporal RNFL compared with males $(n=755)$ in data adjusted for age, height, AL, and ethnicity (mean difference $2.7 \mu \mathrm{m}$, $P=0.0007)$. Figure 1a presents clock hour RNFL thickness for males and females and shows that the sex differences occur mainly in the temporal inferior and superior clock hours (unadjusted data). Females also had smaller disc areas, smaller cup volumes and smaller CDRs (mean differences $0.08 \mathrm{~mm}^{2}, 0.06 \mathrm{~mm}^{3}$, and 0.05 , respectively, all $P \leq 0.004$ ).

In white children compared with East Asian children, RNFL average, superior, temporal, and inferior were thicker in East Asian children, the largest difference was seen in the superior quadrant (mean difference $6.2 \mu \mathrm{m}$, $P<0.0001)$; the nasal quadrant was thicker in white children (mean difference $4.9 \mu \mathrm{m} P<0.0001$ ) (data

Table 2 Distribution of RNFL and optic disc parameters $(n=1521)$

\begin{tabular}{|c|c|c|c|}
\hline & Mean (SD) & Median & Range \\
\hline \multicolumn{4}{|l|}{$R N F L, \mu m$} \\
\hline Average RNFL & $99.4(9.7)^{\mathrm{a}}$ & 99.0 & $61-138$ \\
\hline Temporal & $69.8(11.5)$ & 68.5 & $40-135$ \\
\hline Superior & $124.8(15.9)^{\mathrm{a}}$ & 124.3 & 61-186 \\
\hline Nasal & $74.3(12.6)$ & 73.2 & 31-117 \\
\hline Inferior & $128.5(17.2)$ & 127.7 & 53-214 \\
\hline Clock hour 9 temporal & $54.1(9.1)$ & 53.2 & $31-136$ \\
\hline Clock hour 10 & $83.6(15.7)$ & 82.1 & $41-157$ \\
\hline Clock hour 11 & $139.7(22.2)^{\mathrm{a}}$ & 139.8 & $64-213$ \\
\hline Clock hour 12 superior & $123.2(26.5)^{\mathrm{a}}$ & 122.8 & $48-208$ \\
\hline Clock hour 1 & $111.6(20.7)$ & 109.8 & 50-184 \\
\hline Clock hour 2 & $94.7(18.6)$ & 94.1 & $42-156$ \\
\hline Clock hour 3 nasal & $58.2(11.2)$ & 56.8 & $8-114$ \\
\hline Clock hour 4 & $70.0(15.6)$ & 68.8 & 19-141 \\
\hline Clock hour 5 & $104.8(22.6)$ & 103.0 & 33-191 \\
\hline Clock hour 6 inferior & $139.5(28.1)$ & 138.2 & $52-259$ \\
\hline Clock hour 7 & $141.3(22.4)$ & 142.7 & $61-250$ \\
\hline Clock hour 8 & $71.9(15.6)$ & 69.9 & $38-169$ \\
\hline \multicolumn{4}{|l|}{ Optic disc } \\
\hline Rim area $\left(\mathrm{mm}^{2}\right)$ & $1.50(0.30)$ & 1.47 & $0.50-2.82$ \\
\hline Disc area $\left(\mathrm{mm}^{2}\right)$ & $1.98(0.38)$ & 1.94 & $1.01-4.29$ \\
\hline Cup/disc area ratio & $0.44(0.18)$ & 0.47 & $0.05-0.80$ \\
\hline Vertical cup/disc ratio & $0.42(0.17)$ & 0.45 & $0.05-0.84$ \\
\hline Cup volume $\left(\mathrm{mm}^{3}\right)$ & $0.13(0.14)$ & 0.09 & $0-1.12$ \\
\hline
\end{tabular}

Abbreviation: RNFL, retinal nerve fiber layer.

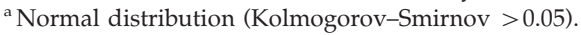


adjusted for age, sex, height, and AL). In Figure 1b, RNFL thickness for the two ethnic groups is presented, demonstrating a thicker RNFL temporally and superiorly in the East Asian group (unadjusted data). The East
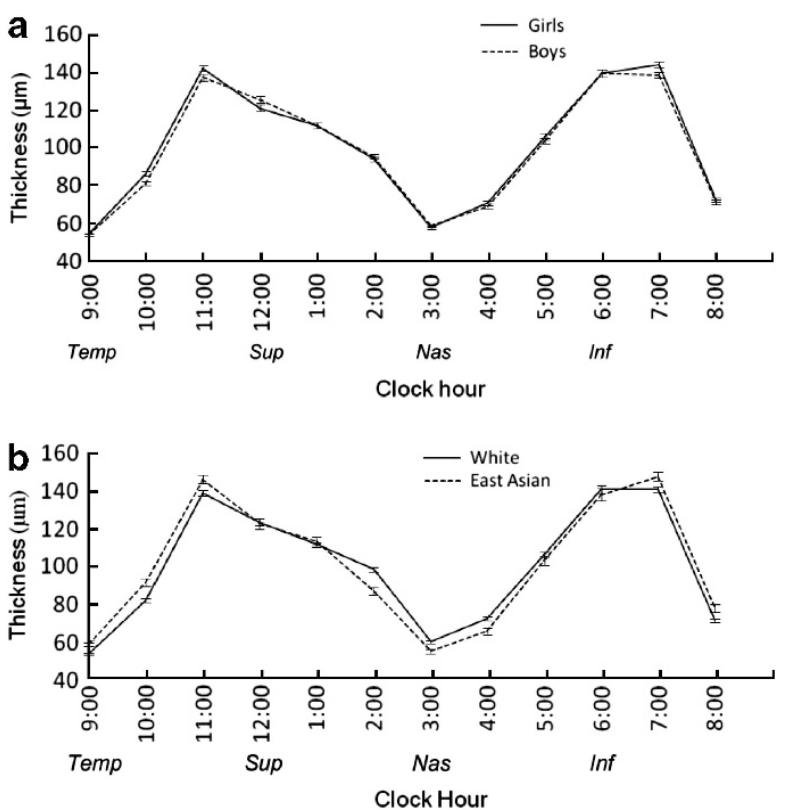

Figure 1 Graphs showing (a) sex and (b) ethnic differences in peripapillary retinal nerve fiber layer mean thickness by clock hours in right eyes. Error bars in both figures are 95\% confidence intervals. Inf, inferior; nas, nasal; sup, superior; temp, temporal.
Asian group was found to have smaller rim areas with larger disc areas, resulting in larger CDR (mean difference $0.08 \mathrm{~mm}^{2}, 0.14 \mathrm{~mm}^{2}$, and 0.11 , respectively, all $P \leq 0.0007)$.

Both greater AL and more myopic refraction were associated with decreased RNFL thickness in data adjusted for age, sex, height, and ethnicity $(P<0.0001)$. Increasing optic disc area and rim areas were found to be associated with greater average RNFL thickness (both $P<0.0001)$. Larger CDR was associated with lower average RNFL thickness $(P=0.02)$. After adjusting for age, sex, height, and ethnicity, the positive association of disc area and rim area with average RNFL thickness was maintained, however there was no significant relationship of a CDR with average $\operatorname{RNFL}(P=0.06)$ after adjustment. Figure 2 demonstrates the relationships of average RNFL thickness with AL, spherical equivalent refraction, and disc parameters.

\section{Discussion}

In this study, we report normative values for RNFL thickness and optic disc parameters measured by Cirrus HD-OCT in a large population-based sample of young adults. We found that the average RNFL and superior RNFL were normally distributed. However, optic disc parameters did not have normal distributions. We also found significant associations between Cirrus
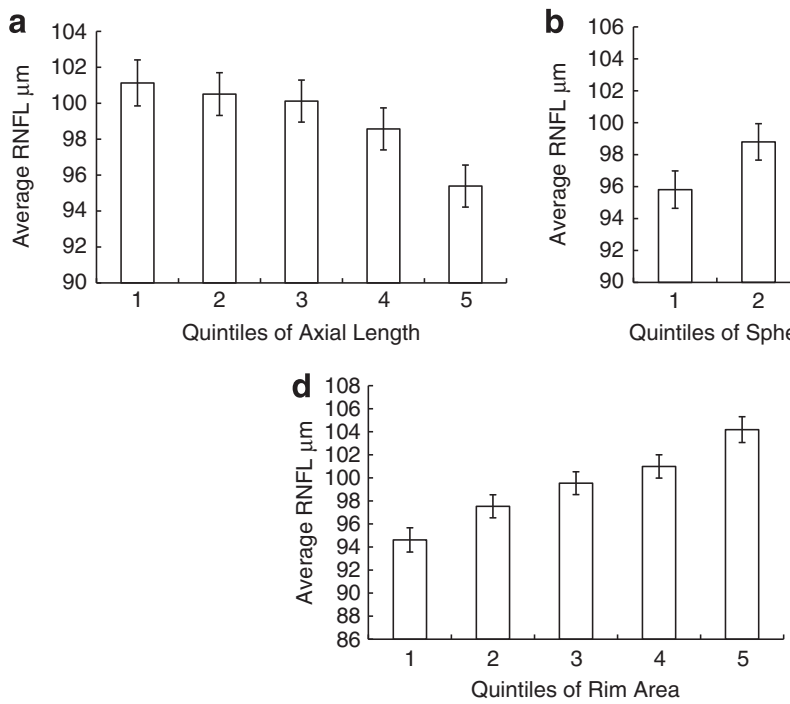
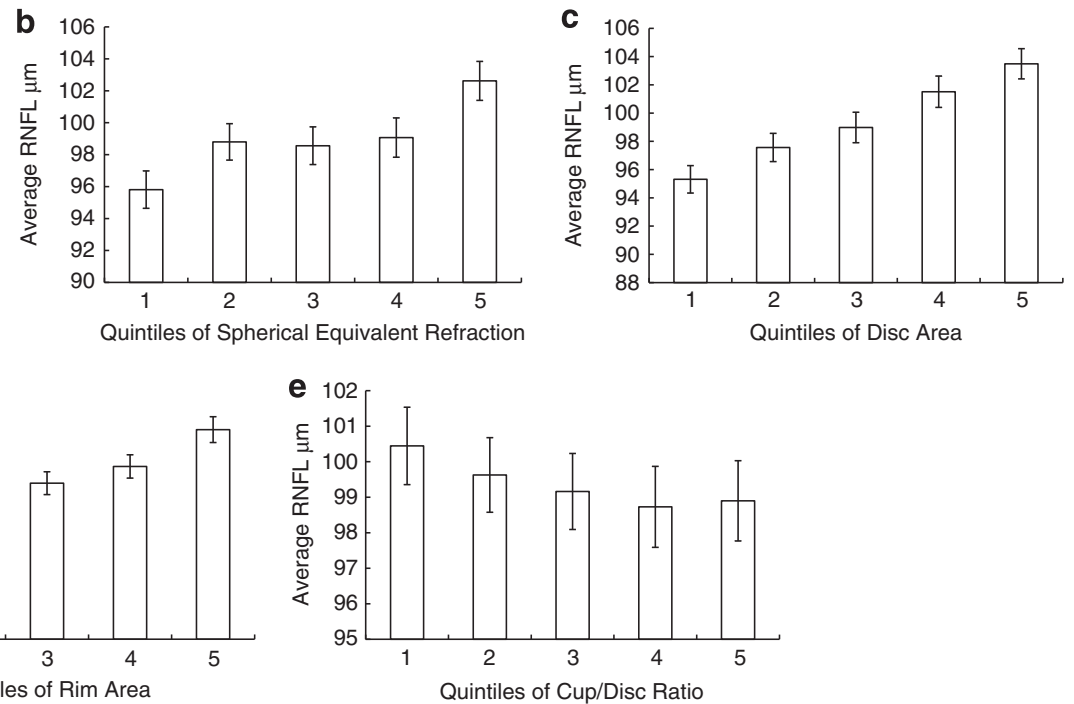

Figure 2 Relationship of average RNFL thickness to (a) quintiles of axial length (b) quintiles of spherical equivalent refraction (c) quintiles of disc area (d) quintiles of rim area (e) quintiles of cup/disc ratio. Error bars represent 95\% confidence intervals. Axial length quintiles $(\mathrm{mm}): 1=20.8-22.89,2=22.9-23.4,3=23.4-23.8,4=23.8-24.3,5=24.3-28.2$. Spherical equivalent quintiles (D): $1=-8.0$ to $-0.6,2=-0.6$ to $0.3,3=0.3-0.6,4=0.6-0.9,5=1.0-6.3$. Disc area quintiles $\left(\mathrm{mm}^{2}\right): 1=1.0-1.7,2=1.7-1.8,3=1.8-2.0$, $4=2.0-2.3,5=2.3-4.3$. Rim area quintiles $\left(\mathrm{mm}^{2}\right): 1=0.5-1.2,2=1.2-1.4,3=1.4-1.5,4=1.5-1.7,5=1.7-1.9$. Cup/disc ratio quintiles: $1=0.1-0.3,2=0.3-0.4,3=0.4-0.5,4=0.5-0.6,5=0.6-0.8$. 
HD-OCT-measured RNFL thickness and ethnicity, AL, and optic disc parameters.

Based on our literature search, few large populationbased studies of RNFL and optic disc parameters measured by Cirrus HD-OCT have been reported. ${ }^{16-20}$ The largest OCT study to date is by Knight et al, ${ }^{16}$ who presented data on 271 normal subjects aged 18-84 years. They had an average RNFL thickness of $94.0 \mu \mathrm{m}$ (SE 0.6) (adjusted for age and disc area) in their multi-ethnic population. This value is similar but slightly less than our value of $99.4 \pm 9.7 \mu \mathrm{m}$. The older population (although data was adjusted for age) and the adjustment for disc area may have accounted for the difference. The disc area and rim area for their total population were $1.81 \mathrm{~mm}^{2}$ and $1.32 \mathrm{~mm}^{2}$, respectively, which are smaller than our values for these parameters. This may be explained by age differences and possible differences in AL between samples. Their values for CDRs were 0.47 (average) and 0.47 (vertical), which were similar to the current study. Hong et al, ${ }^{17}$ who examined 269 (96\% male) normal Korean military personnel aged 19 to 26 years, found an average RNFL thickness of $98.2 \pm 8.6 \mu \mathrm{m}$, which is very similar to our value in males of $98.8 \pm 9.8 \mu \mathrm{m}$ and slightly less than our value for East Asians of $100.1 \pm 9.4 \mu \mathrm{m}$. This study did not present optic disc data.

Mwanza et al ${ }^{18}$ presented optic disc data measured by Cirrus HD-OCT in 146 normal eyes. They found smaller disc areas $\left(1.83 \pm 0.35 \mathrm{~mm}^{2}\right)$ and smaller rim areas $\left(1.27 \mathrm{~mm}^{2}\right)$ and slightly larger CDR $(0.51 \pm 0.16)$ compared with our study. Large studies $(n>100)$ that measured normal disc size using Stratus OCT $\mathrm{OC}^{10,21-25}$ have reported disc areas between $2.34 \pm 0.41$ and

$2.63 \pm 0.55 \mathrm{~mm}^{2}$, which are larger than our value of $1.98 \pm 0.38 \mathrm{~mm}^{2}$. These studies also report cup-disc area ratios between $0.17 \pm 0.11$ and $0.37 \pm 0.20$, which are substantially smaller than our value of $0.44 \pm 0.18$. These discrepancies are most likely due to differences in the scanning pattern and optic disc and cup delineation algorithms between Stratus and Cirrus OCT.

In Table 3, values for OCT measured RNFL thickness in large studies is presented. The studies by Bendschneider et $a^{26}$ using Spectralis HRA + OCT (Heidelberg Engineering, Heidelberg, Germany) and Hirasawa et $a l^{27}$ using the spectral domain Topcon 3D OCT1000 (Tokyo, Japan), report values remarkably similar to those found in our study. We would expect these two studies to measure thinner values, as they included older populations by comparison with our study, and it is known that RNFL thickness decreases with age. 726,28 It should be noted, however, that measurements obtained using either the Spectralis HRA + OCT or Topcon OCT are not interchangeable with those using the Cirrus HD-OCT. ${ }^{29,30}$ The Stratus OCT normative studies presented in Table 3 also have values within $10 \mu \mathrm{m}$ of those presented in our study, which is within the limit of resolution of time domain OCT. ${ }^{7,31}$ Meaningful comparison with Stratus measurements, however, is difficult due to differences in the scanning pattern and segmentation algorithms.

Our study found only small to non-significant sex differences in RNFL thickness with the Cirrus HD-OCT, similar to findings from studies using time domain OCT. ${ }^{7,22,32}$ However, we did find small, but statistically significant, sex differences in optic disc parameters. Most previous studies have reported a lack of association of sex with optic disc parameters. ${ }^{33-35}$ However, larger optic disc size has previously been reported in males, 36,37 consistent with our finding of a slightly larger disc area in males. The average CDR sex difference of 0.05 is not likely to be of any clinical relevance, particularly as the more sensitive parameter of RNFL thickness did not differ between sexes.

Ethnic differences in RNFL thickness were previously reported with older time domain OCT. ${ }^{6-8}$ The thinner nasal RNFL in East Asians could be explained by the

Table 3 Reports of RNFL thickness values measured by OCT in large studies ( $n>100)$

\begin{tabular}{|c|c|c|c|c|c|c|c|c|c|c|}
\hline Paper & OCT & $\begin{array}{l}\text { OCT } \\
\text { type }\end{array}$ & Country & $\mathrm{N}$ & $\begin{array}{c}\text { Age mean (range), } \\
\text { years }\end{array}$ & $\begin{array}{c}\text { Average } \\
\text { RNFL, } \mu m\end{array}$ & $\begin{array}{l}\text { Temporal } \\
\text { RNFL, } \mu m\end{array}$ & $\begin{array}{l}\text { Superior } \\
\text { RNFL, } \mu m\end{array}$ & $\begin{array}{c}\text { Nasal RNFL, } \\
\mu m\end{array}$ & $\begin{array}{c}\text { Inferior } \\
\text { RNFL, } \mu m\end{array}$ \\
\hline Current study & Cirrus & SD & Australia & 1521 & $17.3(16-19)$ & $99.4 \pm 9.7$ & $69.8 \pm 11.5$ & $124.8 \pm 15.9$ & $74.3 \pm 12.6$ & $128.5 \pm 17.2$ \\
\hline Knight et al ${ }^{16}$ & Cirrus & SD & USA & 271 & $46.2(18-84)$ & 94.0 SE:0.6 & 64.0 SE:0.6 & 119.0 SE:0.9 & 69.8 SE:0.7 & 123.2 SE:1.0 \\
\hline Hong et al ${ }^{17}$ & Cirrus & SD & Korea & 269 & $21.3(19-26)$ & $98.6 \pm 8.7$ & & & & \\
\hline Girkin et al ${ }^{19}$ & RTVue & SD & $\mathrm{USA}^{\mathrm{a}}$ & 219 & 53.4 & $101.9 \pm 9.8$ & & & & \\
\hline Hirasawa et al 27 & Topcon & SD & Japan & 251 & $\geq 20$ & $101.9 \pm 8.4$ & $78.6 \pm 13.3$ & $123.9 \pm 13.6$ & $79.6 \pm 13.6$ & $125.5 \pm 13.1$ \\
\hline $\begin{array}{l}\text { Bendschneider } \\
\text { et } a l^{26}\end{array}$ & Spectralis & SD & Germany & 170 & $\sim 20-79$ & $97.2 \pm 9.7$ & $68.8 \pm 11.1$ & $118.0 \pm 14.5$ & $76.4 \pm 15.0$ & $123.7 \pm 16.4$ \\
\hline Turk et al 20 & Spectralis & $\mathrm{SD}$ & Turkey & 107 & $10.5(6-16)$ & $106.5 \pm 9.4$ & & & & \\
\hline Huynh et $a l^{22}$ & Stratus & $\mathrm{TD}$ & Australia & 2132 & $(11.1-14.4)$ & $103.6 \pm 10.6$ & $74.6 \pm 12.8$ & $129.7 \pm 17.5$ & $82.0 \pm 16.7$ & $128.3 \pm 18.6$ \\
\hline Huynh et al ${ }^{9}$ & Stratus & TD & Australia & 1369 & 6.7 & $103.7 \pm 11.4$ & $75.7 \pm 14.7$ & $129.5 \pm 20.6$ & $81.7 \pm 19.6$ & $127.8 \pm 20.5$ \\
\hline El Dairi et al ${ }^{10}$ & Stratus & TD & USA & 286 & $8.6(3-17)$ & $108(92-125)$ & $78(56-105)$ & $143(112-177)$ & $83(56-120)$ & $129(102-160)$ \\
\hline Budenz et $a l^{7}$ & Stratus & TD & USA & 328 & $47.4(18-85)$ & $100.1 \pm 11.6$ & $69.0 \pm 12.7$ & $124.2 \pm 17.9$ & $80.9 \pm 18.1$ & $126.1 \pm 17.8$ \\
\hline
\end{tabular}

Abbreviations: RNFL, retinal nerve fiber layer; SD, spectral domain; SE, standard error; TD, time domain.

${ }^{\text {a }}$ European descent. 
greater prevalence of myopia in this population, which may be associated with a temporal shift in the arcuate nerve fiber bundles. ${ }^{17}$ In a study by Knight et al, ${ }^{16}$ the European/white sample had an average RNFL of $90.1 \mu \mathrm{m}$ (SE 0.8) and their Chinese/East Asian sample had average RNFL of $96.4 \mu \mathrm{m}$ (SE 1.1), compared with our values of $99.5 \pm 9.8 \mu \mathrm{m}$ and $100.1 \pm 9.4 \mu \mathrm{m}$ for these two groups, respectively. Therefore, there is a greater disparity between these ethnic groups compared with our sample, even though their use of disc area adjustment should have reduced the value for the Chinese sample. Because the Knight et al ${ }^{16}$ study had older patients, these differences may suggest that RNFL thinning with age may occur to a greater extent in white compared with East Asian populations.

We found that the East Asian group had larger disc areas, smaller rim areas, and hence larger CDRs than the white sample. In support of our findings, Wang et al ${ }^{38}$ using optic disc photographs reported larger disc size in a Chinese population than in white populations. Also in the SMS, using time domain OCT, we reported that at both 6 and 12 years of age, East Asian children had larger CDRs compared with white children. ${ }^{8}$

We found that increasing AL and more myopic refraction was associated with thinner average RNFL. This is in agreement with previous Cirrus HD-OCT studies, ${ }^{6,39}$ as well as in a study using the Spectralis HRA + OCT. ${ }^{26}$ Studies using the time domain Stratus OCT instrument also reported thinner RNFL with increasing AL or myopic refraction. ${ }^{7,9-12}$ Using the Topcon spectral domain OCT, Hirasawa et al ${ }^{27}$ did not find a relationship with average RNFL thickness or AL in multiple regression analysis. One reason for this discrepancy could be the adjustment for optic disc size in their analysis. RNFL thinning in eyes with longer AL may be due to a magnification effect. ${ }^{7,40}$ The larger projected scan circle in these eyes would alter RNFL measurement further from the disc margin, where the RNFL is thinner. ${ }^{41}$ Regardless of the true relationship between RNFL and AL, it should be noted in clinical practice when using Cirrus HD-OCT that thinner RNFL values will be found in myopic eyes or eyes with longer AL. To account for this effect, a mathematical adjustment for scan enlargement may be utilized by clinicians for patients with very long eyes. ${ }^{42}$

Both larger disc and rim area were found to be associated with increased RNFL thickness. Increasing CDR was associated with decreased RNFL thickness only in unadjusted analysis. Utilizing a spectral domain OCT instrument (OPKO/OTI Spectral OCT/SLO), Mansoori et $a l^{43}$ found no significant association between disc area and RNFL thickness, in conflict with our findings. The reasons for their reported lack of association may be due to the differences in disc margin delineation between the two OCT instruments, or the small sample size of their study $(n=65)$. Our studies also differed with respect to age, with their study including a wider age range of 13-79 years. However, Mansoori et al ${ }^{43}$ reported significantly greater RNFL thickness with increasing rim area and lesser RNFL thickness with increasing CDR, in agreement with our unadjusted findings. The association of a thinner RNFL with increasing CDR is in keeping with the traditional assumption made during clinical assessment of the optic disc for glaucoma screening.

In agreement with our results, a study using Topcon spectral domain $\mathrm{OCT}^{27}$ and studies with the Stratus time domain $\mathrm{OCT}^{7,44}$ have reported increasing RNFL thickness (measured using a 3.4-mm scanning circle) is associated with larger optic disc area. However, these findings may not relate to an actual anatomic relationship as they are not unanimously supported by human histological studies. ${ }^{45,46}$ The fixed diameter of OCT RNFL scanning may introduce an artefact of thicker RNFL measurement in eyes with larger discs, as the RNFL is sampled closer to the disc margin. Hirasawa et $a l^{27}$ used the spectral domain Topcon OCT instrument to study the association of RNFL thickness with different sized scanning circles, and reported that optic disc area was negatively correlated with mean RNFL thickness in the smaller scanning circles $(2.2$ and $2.5 \mathrm{~mm}$ diameter) and positively correlated with mean RNFL thickness in the larger scanning circles (3.4, 3.7, and $4.0 \mathrm{~mm}$ ). This suggests that there may be an even more complex relationship between disc area and RNFL thickness.

Strengths of this study include its large populationbased sample of young adults without confounding ocular disease and the use of uniform examination techniques. A potential weakness of this study is that the scan data are presented without adjustment for scan magnification effects, which could produce abnormal results in individuals at the extremes of AL or refraction. However, as most clinicians rely principally on the raw output of the Cirrus HD-OCT without further calculation, our results may be applied directly to clinical scenarios.

In conclusion, we have presented normative values for Cirrus HD-OCT 4000 measured RNFL and optic disc parameters in a very large population-based sample aged 16-19 years. We further report that RNFL thickness is significantly associated with ethnicity, AL, and optic disc parameters. The values and associations reported in this study can inform clinicians about normal variations in RNFL thickness and optic disc parameters, as measured using the Cirrus HD-OCT and may help to better delineate normal variation from pathological changes. 


\section{Summary}

\section{What was known before}

- Normal ranges for RNFL thickness are provided in the Cirrus HD-OCT in-built database, based only on a sample 284 individuals, only for those above 18 years of age, without stratification for sex and ethnicity.

- There are few large population-based studies using Cirrus HD-OCT providing associations of RNFL parameters with sex, ethnicity, or axial length.

\section{What this study adds}

- Normative data for both RNFL and optic disc parameters measured in a large population-based sample $(n=1521)$ of young adults.

- Data on variation on these parameters with sex ethnicity, axial length, and spherical equivalent refraction.

\section{Conflict of interest}

The authors declare no conflict of interest.

\section{Acknowledgements}

This work was supported by the Australian National Health \& Medical Research Council, Canberra, Australia (Grant 512530).

\section{References}

1 Sommer A, Katz J, Quigley HA, Miller NR, Robin AL, Richter RC et al. Clinically detectable nerve fiber atrophy precedes the onset of glaucomatous field loss. Arch Ophthalmol 1991; 109: 77-83.

2 Quigley HA, Addicks EM, Green WR. Optic nerve damage in human glaucoma. III. Quantitative correlation of nerve fiber loss and visual field defect in glaucoma, ischemic neuropathy, papilledema, and toxic neuropathy. Arch Ophthalmol 1982; 100: 135-146.

3 Schuman JS, Hee MR, Puliafito CA, Wong C, PedutKloizman T, Lin CP et al. Quantification of nerve fiber layer thickness in normal and glaucomatous eyes using optical coherence tomography. Arch Ophthalmol 1995; 113: 586-596.

4 Chen TC, Cense B, Pierce MC, Nassif N, Park BH, Yun SH et al. Spectral domain optical coherence tomography: ultrahigh speed, ultra-high resolution ophthalmic imaging. Arch Ophthalmol 2005; 123: 1715-1720.

5 Wojtkowski M, Srinivasan V, Fujimoto JG, Ko T, Schuman JS, Kowalczyk A et al. Three-dimensional retinal imaging with high-speed ultrahigh-resolution optical coherence tomography. Ophthalmology 2005; 112: 1734-1746.

6 Kang SH, Park KH, Kim JM, Seo JM, Kim DM. Korean normative database for time domain optical coherence tomography to detect localized retinal nerve fiber layer defects (preliminary study). Jpn J Ophthalmol 2010; 54: 144-150.

7 Budenz DL, Anderson DR, Varma R, Schuman J, Cantor L, Savell $\mathrm{J}$ et al. Determinants of normal retinal nerve fiber layer thickness measured by Stratus OCT. Ophthalmology 2007; 114: 1046-1052.

8 Samarawickrama C, Wang JJ, Huynh SC, Pai A, Burlutsky G, Rose KA et al. Ethnic differences in optic nerve head and retinal nerve fibre layer thickness parameters. $\mathrm{Br} \mathrm{J}$ Ophthalmol 2010; 94: 871-876.

9 Huynh SC, Wang XY, Rochtchina E, Mitchell P. Peripapillary retinal nerve fiber layer thickness in a population of 6-yearold children: findings by optical coherence tomography. Ophthalmology 2006; 113: 1583-1592.

10 El Dairi MA, Asrani SG, Enyedi LB, Freedman SF. Optical coherence tomography in the eyes of normal children. Arch Ophthalmol 2009; 127: 50-58.

11 Nagai-Kusuhara A, Nakamura M, Fujioka M, Fujioka M, Tatsumi Y, Negi A. Association of retinal nerve fibre layer thickness measured by confocal scanning laser ophthalmoscopy and optical coherence tomography with disc size and axial length. Br J Ophthalmol 2008; 92: 186-190.

12 Leung MM, Huang RY, Lam AK. Retinal nerve fiber layer thickness in normal Hong Kong Chinese children measured with optical coherence tomography. J Glaucoma 2010; 19: 95-99.

13 Knight OJ, Chang RT, Feuer WJ, Budenz DL. Comparison of retinal nerve fiber layer measurements using time domain and spectral domain optical coherent tomography. Ophthalmology 2009; 116: 1271-1277.

14 Ferris FL III, Kassoff A, Bresnick GH, Bailey I. New visual acuity charts for clinical research. Am J Ophthalmol 1982; 94: 91-96.

15 Littell RC, Milliken GA, Stroup WW, Wolfinger RD, Schabenberger O. SAS for Mixed Models. 2nd edn. SAS Institute Inc: Cary, NC, 2006.

16 Knight OJ, Girkin CA, Budenz DL, Durbin MK, Feuer WJ. Cirrus OCT Normative Database Study Group. Effect of race, age, and axial length on optic nerve head parameters and retinal nerve fiber layer thickness measured by cirrus HD-OCT. Arch Ophthalmol 2012; 130: 312-318.

17 Hong SW, Ahn MD, Kang SH, Im SK. Analysis of peripapillary retinal nerve fiber distribution in normal young adults. Invest Ophthalmol Vis Sci 2010; 51: 3515-3523.

18 Mwanza JC, Oakley JD, Budenz DL, Anderson DR. Ability of cirrus HD-OCT optic nerve head parameters to discriminate normal from glaucomatous eyes. Ophthalmology 2011; 118: 241-248.

19 Girkin CA, McGwin G Jr, Sinai MJ, Sekhar GC, Fingeret M, Wollstein $\mathrm{G}$ et al. Variation in optic nerve and macular structure with age and race with spectral-domain optical coherence tomography. Ophthalmology 2011; 118: 2403-2408.

20 Turk A, Ceylan OM, Arici C, Keskin S, Erdurman C, Durukan AH et al. Evaluation of the nerve fiber layer and macula in the eyes of healthy children using spectraldomain optical coherence tomography. Am J Ophthalmol 2012; 153: 552-559.

21 Nagai-Kusuhara A, Nakamura M, Tatsumi Y, Nakanishi Y, Negi A. Disagreement between Heidelberg Retina Tomograph and optical coherence tomography in assessing optic nerve head configuration of eyes with band atrophy and normal eyes. Br J Ophthalmol 2008; 92: 1382-1386.

22 Huynh SC, Wang XY, Burlutsky G, Rochtchina E, Stapleton F, Mitchell P. Retinal and optic disc findings in adolescence: a population-based OCT study. Invest Ophthalmol Vis Sci 2008; 49: 4328-4335.

23 Dacosta S, Bilal S, Rajendran B, Janakiraman P. Optic disc topography of normal Indian eyes: an assessment using optical coherence tomography. Indian J Ophthalmol 2008; 56: 99-102.

24 Leung CK, Cheng AC, Chong KK, Leung KS, Mohamed S, Lau CS et al. Optic disc measurements in myopia with optical coherence tomography and confocal scanning laser 
ophthalmoscopy. Invest Ophthalmol Vis Sci 2007; 48: 3178-3183.

25 Cankaya AB, Elgin U, Batman A, Acaroglu G. Relationship between central corneal thickness and parameters of optic nerve head topography in healthy subjects. Eur J Ophthalmol 2008; 18: 32-38.

26 Bendschneider D, Tornow RP, Horn FK, Laemmer R, Roessler CW, Juenemann AG et al. Retinal nerve fiber layer thickness in normals measured by spectral domain OCT. J Glaucoma 2010; 19: 475-482.

27 Hirasawa H, Tomidokoro A, Araie M, Konno S, Saito H, Iwase A et al. Peripapillary retinal nerve fiber layer thickness determined by spectral-domain optical coherence tomography in ophthalmologically normal eyes. Arch Ophthalmol 2010; 128: 1420-1426.

28 Kanamori A, Escano MF, Eno A, Nakamura M, Maeda H, Seya R et al. Evaluation of the effect of aging on retinal nerve fiber layer thickness measured by optical coherence tomography. Ophthalmologica 2003; 217: 273-278.

29 Leite MT, Rao HL, Weinreb RN, Zangwill LM, Bowd C, Sample PA et al. Agreement among spectral-domain optical coherence tomography instruments for assessing retinal nerve fiber layer thickness. Am J Ophthalmol 2011; 151: 85-92.

30 Huang J, Liu X, Wu Z, Guo X, Xu H, Dustin L et al. Macular and retinal nerve fiber layer thickness measurements in normal eyes with the Stratus OCT, the Cirrus HD-OCT, and the Topcon 3D OCT-1000. J Glaucoma 2011; 20: 118-125.

31 Hee MR, Izatt JA, Swanson EA, Huang D, Schuman JS, Lin $\mathrm{CP}$ et al. Optical coherence tomography of the human retina. Arch Ophthalmol 1995; 113: 325-332.

32 Leung CK, Mohamed S, Leung KS, Cheung CY, Chan SL, Cheng DK et al. Retinal nerve fiber layer measurements in myopia: An optical coherence tomography study. Invest Ophthalmol Vis Sci 2006; 47: 5171-5176.

33 Quigley HA, Brown AE, Morrison JD, Drance SM. The size and shape of the optic disc in normal human eyes. Arch Ophthalmol 1990; 108: 51-57.

34 Jonas JB, Gusek GC, Naumann GO. Optic disc, cup and neuroretinal rim size, configuration and correlations in normal eyes [published erratum appears in Invest Ophthalmol Vis Sci 1991; 32(6):1893 and 1992; 32(2):474-5]. Invest Ophthalmol Vis Sci 1988; 29: 1151-1158.

35 Chihara E, Chihara K. Covariation of optic disc measurements and ocular parameters in the healthy eye. Graefes Arch Clin Exp Ophthalmol 1994; 232: 265-271.
36 Ramrattan RS, Wolfs RC, Jonas JB, Hofman A, de Jong PT. Determinants of optic disc characteristics in a general population: The Rotterdam Study. Ophthalmology 1999; 106: 1588-1596.

37 Varma R, Tielsch JM, Quigley HA, Hilton SC, Katz J, Spaeth GL et al. Race-, age-, gender-, and refractive error-related differences in the normal optic disc. Arch Ophthalmol 1994; 112: 1068-1076.

38 Wang Y, Xu L, Zhang L, Yang H, Ma Y, Jonas JB. Optic disc size in a population based study in northern China: the Beijing Eye Study. Br J Ophthalmol 2006; 90: 353-356.

39 Wang G, Qiu KL, Lu XH, Sun LX, Liao XJ, Chen HL et al. The effect of myopia on retinal nerve fibre layer measurement: a comparative study of spectral-domain optical coherence tomography and scanning laser polarimetry. Br J Ophthalmol 2011; 95: 255-260.

40 Wakitani Y, Sasoh M, Sugimoto M, Ito Y, Ido M, Uji Y. Macular thickness measurements in healthy subjects with different axial lengths using optical coherence tomography. Retina 2003; 23: 177-182.

41 Cohen MJ, Kaliner E, Frenkel S, Kogan M, Miron H, Blumenthal EZ. Morphometric analysis of human peripapillary retinal nerve fiber layer thickness. Invest Ophthalmol Vis Sci 2008; 49: 941-944.

42 Kang SH, Hong SW, Im SK, Lee SH, Ahn MD. Effect of myopia on the thickness of the retinal nerve fiber layer measured by Cirrus HD optical coherence tomography. Invest Ophthalmol Vis Sci 2010; 51: 4075-4083.

43 Mansoori T, Viswanath K, Balakrishna N. Correlation between peripapillary retinal nerve fiber layer thickness and optic nerve head parameters using spectral domain optical coherence tomography. J Glaucoma 2010; 19: 604-608.

44 Savini G, Zanini M, Carelli V, Sadun AA, Ross-Cisneros FN, Barboni P. Correlation between retinal nerve fibre layer thickness and optic nerve head size: an optical coherence tomography study. Br J Ophthalmol 2005; 89: 489-492.

45 Jonas JB, Schmidt AM, Muller-Bergh JA, SchlötzerSchrehardt UM, Naumann GO. Human optic nerve fiber count and optic disc size. Invest Ophthalmol Vis Sci 1992; 33: 2012-2018.

46 Varma R, Skaf M, Barron E. Retinal nerve fiber layer thickness in normal human eyes. Ophthalmology 1996; 103: 2114-2119. 